\title{
NASH EQUILIBRIUM AND THE HISTORY OF ECONOMIC THEORY
}

by Roger B. Myerson

first version, April 1996

revised, March 1999

\begin{abstract}
John Nash's formulation of noncooperative game theory was one of the great breakthroughs in the history of social science. Nash's work in this area is reviewed in its historical context, to better understand how the fundamental ideas of noncooperative game theory were developed and how they changed the course of economic theory. JEL Classification numbers: B20, C72
\end{abstract}

Author's address: Department of Economics, University of Chicago, 1126 E 59th Street, Chicago, IL 606037. E-mail: myerson@uchicago.edu URL: http://home.uchicago.edu/ rmyerson/ This paper is published in the Journal of Economic Literature 36:1067-1082 (1999), which is the only definitive repository of the content that has been certified and accepted after peer review. 


\section{NASH EQUILIBRIUM AND THE HISTORY OF ECONOMIC THEORY \\ by Roger B. Myerson, Northwestern University}

\section{Looking back on an intellectual revolution}

November 16, 1999 marks the fiftieth anniversary of the day that John Nash's first paper on noncooperative equilibrium was received by the editorial offices of the Proceedings of the National Academy of Sciences. The fiftieth anniversary of a major event can be a good time to look back at it, when we are still linked to it by living memories, but we have enough distance to see some of its broader historical significance.

From this perspective, Nash's theory of noncooperative games should now be recognized as one of the outstanding intellectual advances of the twentieth century. The formulation of Nash equilibrium has had a fundamental and pervasive impact in economics and the social sciences which is comparable to that of the discovery of the DNA double helix in the biological sciences. Yet even now, there are still current books on the history of economic thought that fail to allocate even one full page to Nash's work (see Niehans, 1990), and prominent scholars can search for a "consilient" unification of social science with virtually no regard for the real unification that has been provided by noncooperative game theory (see Wilson, 1998). So it is appropriate that we should now re-examine Nash's work in its broader historical context, to see how a few short papers by a young mathematician achieved one of the great watershed breakthroughs in the history of social science.

Weintraub (1992) offers a good overview of the early history of game theory, with a particular focus on the work of von Neumann and Morgenstern (see also Morgenstern, 1976). 
Since 1994, when the Nobel Memorial Prize in Economic Sciences was awarded to John Nash, John Harsanyi, and Reinhard Selten, there have been a number of essays in appreciation of Nash's work; see Leonard (1994), Kuhn (1994), Milnor (1995), Rubinstein (1995), van Damme and Weibull (1995), Myerson (1996), and Binmore's introduction to the collected game-theory papers of Nash (1996). A detailed biography of John Nash has been written by Sylvia Nasar (1998).

In this paper, to show how Nash's work was a major turning-point in the history of economic thought, we try to place his contributions in their broader historical context. So in addition to reviewing Nash's most important contributions, we also examine some of Nash's precursors and followers. Our goal is to better appreciate how economic theory was transformed by Nash's ideas, and to understand why these ideas were developed at his point in time and were not seen earlier.

To understand both the importance of Nash's work and how it could be overlooked in histories of economic thought, we should begin with the very definition of economics itself. A generation before Nash could have accepted a narrower definition of economics, as a specialized social science concerned with the production and allocation of material goods. With this narrower definition, Nash's work could be seen at first as mathematical research near the boundaries of economics. But today economists can define their field more broadly, as being about the analysis of incentives in all social institutions. When we ask how this change occurred, we find that Nash's contributions had a central role in it, although this process of redefining the scope of economics has a long history before and after him.

Such an ambiguity in the definition of economics was recognized by Augustin Cournot 
(1838, section 5) when he wrote,

"From a standpoint of mere etymology, whatever appertains to the organization of society belongs to the field of Political Economy; but it has become customary to use this last term in a sense much more restricted... being occupied principally with the material wants of mankind."

Indeed, the term economics was first used by philosophers of ancient Greece who were interested in studying all the institutions of civilized society and did not develop an academic specialization in the study of markets alone. But in the century before Cournot, an increasing number of scholarly writers began to develop mathematical theories about the growth and allocation of national income. The production and distribution of material goods seemed more amenable to mathematical analysis than other aspects of the social system, because flows of money and goods in a market are readily quantifiable, and because systems of equations for prices and quantities in a market can be derived from no-arbitrage and flow-balance conditions. So it was natural then for economics to develop as a special branch of moral philosophy that focused on analytical approaches to questions about the production and distribution of material goods.

In the century following Cournot (1838) (in what Niehans, 1990, calls the Marginalist Era), economic theorists worked to develop a deeper theory of the determinants of supply and demand in markets, based on models of rational competitive decision-making by producers and consumers. Then, as economists learned how to think systematically about rational competitive decision-making, it became natural to think about the application of such rational-choice analysis to social problems other than production and allocation of material goods. But nonmarket applications of rational-choice analysis required a more general analytical framework for doing 
rational-choice analysis without the traditional market structures of goods and prices. The search for such a general framework was undertaken by the early game theorists. Nash's theory of noncooperative games was the critical breakthrough in this process of extending the scope of rational-choice analysis to general competitive situations.

\section{Economics, rationality, and institutions}

So to understand the importance of noncooperative game theory, we need to appreciate why rational-choice analysis should be so important in economics. This assumption of perfect rationality is certainly imperfect as a description of real human behavior. Experimental studies of decision-making regularly find inconsistent and foolish behavior that violates the predictions of perfect rationality. So we must ask why this extreme assumption of perfect rationality has been so fruitful for economic analysis in a way that no other theory of human behavior has been able to challenge.

One answer is that reliably accurate and analytically tractable theories of the inconsistency and foolishness in human behavior simply have not yet been developed, and so our best analytical models are based on the rationality assumption for lack of any better foundation. A second answer is that, in the long run when the stakes are high, we should expect people's behavior to more closely approximate the ideal of perfect rationality than in laboratory experiments. But we can find a third and more compelling answer when we recognize that the functional goal of social science is not just to predict human behavior in the abstract, but to analyze social institutions and evaluate proposals for institutional reform.

When our task is to look for potential flaws in a social institution, it can be very helpful to 
analyze the institution under an assumption that the agents in the institution are not themselves flawed. Otherwise, if we find that flawed individuals may come to grief in this institutional structure, we cannot say whether our finding is an argument for reform of the institution or an argument for better education of individuals. Thus economists have found it useful to assume a certain perfection of individuals, in order to see more clearly when social problems must be solved by institutional reform. (Questions of how to improve the education of individuals can be identified as the domain of psychologists, who naturally find such individual-perfection assumptions to be much less useful.)

This argument can be sharpened to show why this individual-perfection assumption should be one of intelligent rational maximization, as in the models of noncooperative game theory. To do any kind of analytical social theory, we must formulate a model that includes both a description of the institutions that we are studying and a prediction of individual's likely behavior in these institutions. To be able to handle normative questions, there must also be some concept of human welfare in our model. If we assume that some individuals are not motivated to maximize their own welfare (as measured in our model) or that some individuals do not understand their environment (as predicted in our analysis), then any loss of welfare that we find in our analysis can be blamed on such dysfunctional or misinformed individual behavior, rather than on the structure of social institutions. Thus an argument for reform of social institutions (rather than for reeducation of individuals) is most persuasive when it is based on a model which assumes that individuals intelligently understand their environment and rationally act to maximize their own welfare. So applied social theorists should find it useful to scrutinize social institutions under the assumption that each member of society will act, within his (or her) domain 
of control, to maximize welfare as he (or she) evaluates it, given the predicted behavior of others. The concept of Nash equilibrium is, in its essence, the general formulation of this assumption.

Nash (1950b) formally defined an equilibrium of a noncooperative game to be a profile of strategies, one for each player in the game, such that each player's strategy maximizes his expected utility payoff against the given strategies of the other players. If we can predict the behavior of all the players in such a game, then our prediction must be a Nash equilibrium, or else it would violate this assumption of intelligent rational individual behavior. That is, if our predicted behavior does not satisfy the conditions for Nash equilibrium, then there must be at least one individual whose expected welfare could be improved simply by re-educating him to more effectively pursue his own best interests, without any other social change.

Notice that this argument does not prove that Nash equilibrium should be the only methodological basis for analysis of social institutions. But it does explain why studying Nash equilibria should be a fruitful part of the critical analysis of almost any kind of social institution.

\section{Nash's precursors: Cournot, Borel, and von Neumann}

Given that Nash equilibrium can be a useful solution concept for the analysis of incentives in any social institution, and given the apparent logical simplicity of Nash equilibrium, it may seem surprising that this solution concept was not articulated much earlier in the history of social science. Reformulating ideas of Machiavelli and Hobbes with the models of noncooperative game theory can be an interesting and rewarding exercise. But the first clear application of Nash equilibrium in a precise mathematical model comes in the work of Cournot.

In a brilliant pathbreaking book, Cournot (1838) constructed a theory of oligopolistic 
firms that includes monopolists and perfect competitors as limiting extremes. He developed game models of oligopolistic competition, which he analyzed by the methodology of Nash equilibrium. But of course he was writing more than a century before Nash, and so we must ask whether Cournot should get the credit for the noncooperative equilibrium. Indeed, some economists have suggested that, rather than "Nash equilibrium,"we should speak of "Cournot-Nash equilibrium" or even "Cournot equilibrium."

Such terminology would be very misleading, however. We may speak of Cournot as the founder of oligopoly theory, but to give him credit for the fundamental solution concept of noncooperative game theory would be to confuse one application of a methodology with its general formulation. This distinction is one which Cournot would have appreciated. He wrote a short book on mathematical economics, but he wrote at greater length on the philosophy of science and the foundations of our knowledge. If he had recognized that noncooperative game theory can provide a general unifying structure for analyzing all kinds of social institutions, he would have wanted to write about it more than anyone else in his generation.

But he did not see it. Cournot did not develop the conceptual distinction between the formulation of his specific game models and the general methodology used to analyze them. Cournot first analyzed competition among firms that compete to sell the same consumer good, and then he analyzed a second model of producers of complementary inputs for a manufactured good. In the analysis of the latter model, Cournot did remark that he was applying the same method of reasoning that he had used in the first model. But beyond this introductory remark, Cournot made no attempt to articulate a general methodology of equilibrium analysis.

Indeed, far from finding a general analytical methodology in Cournot, readers from 
Bertrand (1883) to Fellner (1949) found specific models of oligopoly which had some interesting applied predictions, but which seemed to make some invalid assumptions. (See Leonard, 1994.) In particular, once Cournot has shown that the optimal output of firm 2 depends on the output of firm 1, it may seem irrational for the manager of firm 1 to assume that 2 's output would remain fixed if he changed 1's output. Until this critique could be answered, Cournot's methodology did not look like a compelling general theory of rational behavior.

The answer to this critique begins with a remark in a short paper by the mathematician Emile Borel (1921). Considering a class of simple two-person zero-sum games, Borel set out "to investigate whether it is possible to determine a method of play that is better than all others." While laying out the formal structures of his model, Borel remarked that a method of play should be understood here to mean "a code that determines for every possible circumstance (supposed finite in number) exactly what the person should do." Having made this remark, Borel felt free to ignore the extensive temporal structures of games. So in this and subsequent papers on games (see Frechet, 1953), Borel simply represented each game by a matrix of numbers that specify the expected value for each player for each pair of such methods-of-play.

John von Neumann's (1928) first great paper on game theory begins with a section entitled "General Simplifications" that lays out a full development of this idea. In this section, von Neumann explicitly formulated a general model of extensive games, in which players move sequentially over time with imperfect information about each others' previous moves. Because players may get some information about other players' previous moves, we cannot assume that players' moves are independent in such extensive games. But following Borel, von Neumann then defined a strategy for each player to be a complete plan that specifies a move for the player, 
at each stage where he is active, as a function of his information at that stage. (Von Neumann's

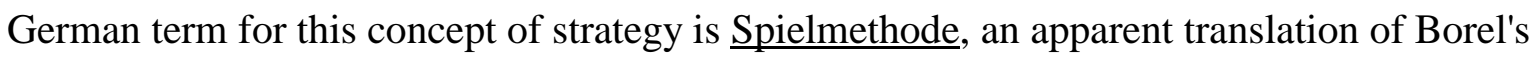
French phrase méthode de jeu.) A rational player can choose his strategy before the game begins, with no loss of generality, because a strategy lets him specify a different move for every situation in which he might find himself during the game. But "before the game begins" means before any consequences of other players' decisions can be observed. So in his General Simplifications section, von Neumann concludes that each player must choose his strategy without being informed of the other players' strategy choices. ("Jeder hat seinen Entschluss zu fassen, ohne ueber die Resultate der Wahlen seiner Mitspieler Kenntnis zu haben.")

Thus von Neumann (1928) argued that virtually any competitive game can be modeled by a mathematical game with the following simple structure: There is a set of players, each player has a set of strategies, each player has a payoff function from the Cartesian product of these strategy sets into the real numbers, and each player must choose his strategy independently of the other players. Von Neumann and Morgenstern (1944) call this structure the normal form for representing general extensive games. Once we understand this construction of the normal form, we can see that there may be no loss of generality in studying games where players make their strategic decisions independently.

This insight is what allows us today to accept Cournot's basic assumption that competitors make their decisions independently. Perhaps firm 2 can base its production next year on firm 1's production this year; but that just means that firm 2 has a larger strategy space than Cournot admitted. At the level of strategic planning, we can still assume that firm 2 chooses its strategy independently of firm 1's strategy choice. This idea of general strategic independence 
was not recognized by Cournot (1838) or by economic theorists in the century following him until they learned this idea from von Neumann. Although von Neumann (1953) gave Borel prior credit for the basic concept of a strategy, it is hard to see how economists could have learned the principle of general strategic independence from Borel's brief remark. So the full exposition of the normal form and the concept of strategic independence can be counted as von Neumann's first important contribution to game theory.

Von Neumann did not consistently apply this principle of strategic independence, however. In his analysis of games with more than two players, von Neumann (1928) assumed that players would not simply choose their strategies independently, but would coordinate their strategies in coalitions. Furthermore, by his emphasis on max-min values, von Neumann was implicitly assuming that any strategy choice for a player or coalition should be evaluated against the other players' rational response, as if the others could plan their response after observing this strategy choice. Before Nash, however, no one seems to have noticed that these assumptions were inconsistent with von Neumann's own argument for strategic independence of the players in the normal form.

Von Neumann (1928) also added two restrictions to his normal form that severely limited its claim to be a general model of social interaction for all the social sciences: He assumed that payoff is transferable, and that all games are zero-sum. To see why he added these seemingly unnecessary restrictions, we must recall his second great contribution to game theory: the minimax theorem.

In the minimax theorem, von Neumann (1928) showed the general existence of minimax solutions in randomized strategies for finite two-person zero-sum games. For such games, the 
minimax theorem is logically equivalent to the existence of a Nash equilibrium. Von Neumann's (1928) proof of the minimax theorem uses an ingenious trick to reduce the problem to a series of one-dimensional steps, which are proven by applying a one-dimensional form of the later Kakutani (1941) fixed-point theorem. (After von Neumann used the Brouwer fixed-point theorem in the analysis of an economic growth model in 1937, it was natural for Kakutani to introduce his fixed-point theorem as the generalization of these two mathematical techniques that von Neumann had used to prove existence of solutions in economic models.) But von Neumann formulated the minimax theorem as an equality between the values that each player can guarantee himself, regardless of what the opponent might do, not as mutual optimality among a particular pair of strategies. Thus formulated as an equality of guaranteed max-min values, the theorem could not be extended beyond the two-person zero-sum case.

Following Borel (1921), von Neumann (1928) recognized that the existence of minimax solutions for two-person zero-sum games could not be proven unless randomized strategies were admitted. To analyze games with randomization, however, we need a theory of how players make decisions under uncertainty. Borel and von Neumann used the traditional assumption (following Bernoulli, 1738) that, when there is uncertainty, each player wants to maximize the expected value of his payoff. But von Neumann was uncomfortable with this assumption. Expected value comparisons required a kind of cardinal measurability of payoffs, which contradicted the contemporary wisdom among economic theorists who then understood utility as a purely ordinal concept. In 1928 and again in his 1944 book with Morgenstern, von Neumann tried to justify this cardinal utility assumption by identifying all payoffs with monetary transfer payments, which led him to the restriction that payoff is transferable and all games are zero-sum. 
The fact that the zero-sum restriction also gave him the two-person minimax theorem was probably what committed him intellectually to these restrictions, but the discussion in von Neumann and Morgenstern (1944, Section 2.1.1) suggests that the initial motivation was to defer the problem of measuring utilities.

In 1947 (in their book's second edition), von Neumann and Morgenstern published their third great contribution to game theory: the axiomatic derivation of expected-utility maximization from a substitution argument. This new justification for measurable utility should have prompted them to consider dropping their restrictive assumption that payoffs must be transferable and zero-sum in all games, but they did not.

So by 1948 von Neumann and Morgenstern had developed many fundamental elements for a theory of games: the extensive and normal forms linked by the concept of a strategy, the use of fixed-point theorems to prove existence of solutions for games with randomization, and a general derivation of the expected utility criterion for individual decision-making. But in their drive to assemble all these new ideas in a general unified theory of games, von Neumann and Morgenstern did not apply them consistently. So when John Forbes Nash, Jr., arrived at Princeton as a new graduate student, the time was ripe for a talented young mathematician who had the audacity to reconsider the whole structure of game theory on his own, to take these elements apart and reassemble them correctly.

\section{Nash's reconstruction of game theory}

Nash's first great contribution was his theory of two-person bargaining. By a beautiful axiomatic argument, Nash (1950a) introduced a bargaining solution that was virtually 
unanticipated in the literature, and was the first work in game theory that did not assume transferable utility. Indeed, most subsequent work on cooperative games with nontransferable utility has been based on Nash's approach to the bargaining problem (see Myerson, 1992).

Nash's bargaining theory builds on the insight that individuals' utility scales can be defined up to separate increasing linear transformations, but this result follows only from von Neumann and Morgenstern's 1947 derivation of utility. Thus, Nash's bargaining solution could not have been appreciated before 1947. It is remarkable that Nash found this solution so quickly thereafter. Nash's earliest conception of it actually came in 1948 when he was an undergraduate taking a course on international trade (Nash, 1996). Nash may have started by thinking about a problem of international bargaining where countries have different inconvertible currencies, but there is no hint of that (less interesting) question in Nash's (1950a) presentation, which actually begins with an elegant exposition of von Neumann and Morgenstern's utility theory.

Then, on November 16, 1949, the Proceedings of the National Academy of Sciences received from Nash a short note, which was published the next year (1950b). In this two-page note, Nash gave the general definition of equilibrium for normal-form games, and he neatly sketched an argument using the Kakutani fixed-point theorem to prove that equilibria in randomized strategies must exist for any finite normal-form game. In his Princeton doctoral dissertation, Nash continued to work on proofs using the Brouwer fixed-point theorem, which was then better known, but the Kakutani theorem has since become standard tool for economists in part because of its use by Nash (1950b). (Early proofs of the existence of general Walrasian equilibrium in price theory were directly inspired by Nash's existence theorem in game theory.)

For his doctoral thesis, Nash worked on a fuller development of the idea of 
noncooperative equilibrium. Most of his thesis was published (in more polished form) as Nash (1951) in the Annals of Mathematics, except for one section of the thesis on the motivation and interpretation of Nash equilibrium, which was omitted from the 1951 paper but is now published in the collected works (Nash, 1996, pages 32-33).

Having formulated the general definition of equilibrium for noncooperative games, and having proven the general existence of equilibria for such games in his 1950 note, it might have seemed that there was little more for Nash to do for a dissertation on noncooperative game theory, other than work out some examples. Indeed, Nash (1951) presented a number of interesting examples, illustrating problems which have concerned game theorists ever since, including a game with one Pareto-inefficient equilibria like the Prisoners' Dilemma, a game with multiple equilibria, and a game with an unstable equilibrium that shows the need for refinements such as perfect equilibrium. Nash (1951) also analyzed a three-person poker game in extensive form, where he applied Kuhn's (1950) new methodology of studying behavioral strategies (in which randomizations occurs at each stage of the game), rather than the mixed strategies of von Neumann (in which each player is supposed to make just one big randomization at the beginning of the game).

But the most important new contribution of Nash (1951), fully as important as the general definition and the existence proof of Nash (1950b), was his argument that this noncooperative equilibrium concept, together with von Neumann's normal form, gives us a complete general methodology for analyzing all games. Referring to the other "cooperative" theories of von Neumann and Morgenstern, Nash (1951) wrote:

"This writer has developed a 'dynamical' approach to the study of cooperative 
games based on reduction to non-cooperative form. One proceeds by constructing a model of the larger pre-play negotiation so that the steps of negotiation become moves in a larger non-cooperative game ... describing the total situation."

Thus Nash applied the normalization argument to show that any other theory of games should be reducible to equilibrium analysis.

With this step, Nash carried social science into a new world where a unified analytical structure can be found for studying all situations of conflict and cooperation. Von Neumann's normal form is our general model for all games, and Nash's equilibrium is our general solution concept. Nash (1951) also noted that the assumption of transferable utility can be dropped without loss of generality, because possibilities for transfer can be put into the moves of the game itself, and he dropped the zero-sum restriction that von Neumann had imposed.

In his 1953 paper, Nash offered an application of his program for reducing cooperative game theory to noncooperative equilibrium analysis. He modeled the two-person bargaining process by a simple game of simultaneous demands. This game has an infinite number of Nash equilibria, but Nash gave an ingenious perturbational argument (anticipating later perturbational refinements like perfectness of Selten, 1975, and stability of Kohlberg and Mertens, 1986) that identified a unique stable equilibrium coinciding with the bargaining solution that he previously derived axiomatically.

To see the fundamental change in game theory that Nash made, one can go back and read the reviews of von Neumann and Morgenstern's book written before Nash (Hurwicz, 1945, Kaysen, 1945, Marshak, 1946, Wald, 1947, and Stone, 1948). The best practical economic application of game theory that these reviewers found was a simple three-person game involving 
one seller of a single valuable object and two potential buyers. As Stone (1948) described this game, one of the buyers has an intrinsically greater willingness to pay for the object, but the other has significantly more information about the prices of similar objects. From the perspective of modern information economics, this sounds like a rather interesting example of an auction with asymmetric information. But to apply the methodology of von Neumann and Morgenstern, Stone (1948) felt obliged to plunge into coalitional analysis, where all the interesting informational questions disappeared.

Indeed, the problems of communication must disappear in a world where people first choose their friends, before getting any information, and thereafter act only as part of a perfectly coordinated union with their friends. But Nash taught us to keep our eyes on the process of individual decision-making, even in a negotiation to collude. If the buyers in Stone's auction can meet to arrange collusive bids, the Nash program directs us to view this collusion as the outcome of a process of communication where each player has choices about what to say. In this process, the more-informed buyer may try to mislead the less-informed buyer about the value of the object, and the less-informed buyer should rationally take this possibility into account. Thus, the Nash program opened the door to the questions of information economics, while the von Neumann program led away from it.

\section{Subsequent development of noncooperative game theory}

The impact of Nash's reconstruction of game theory spread slowly. At first, more attention was focused on the cooperative analysis that von Neumann favored. (The short perfunctory reference to Nash's work in the preface to the 1953 edition of von Neumann and 
Morgenstern's book is particularly disappointing.) Later, as more people recognized the importance of Nash's program, it became apparent that there were a number of technical problems that needed further study before noncooperative game theory could meet its promise as a general analytical methodology for applied work.

The adequacy of the normal form remained a central question in noncooperative game theory. We have seen that the generality of Nash equilibrium as a solution concept could not be accepted until the normal form was understood to be a general model for all games. But as Nash equilibrium became more commonly applied, limitations of normal-form analysis became apparent. So the further development of noncooperative game theory required more careful study of the extensive form. This development began with the introduction of behavioral strategies and the general reformulation of the extensive form by Harold Kuhn $(1950,1953)$.

Reinhard Selten $(1965,1975)$ showed that, for many games, normal-form Nash equilibrium analysis can sometimes generate too many equilibria, including some equilibria that seem irrational when re-examined in the extensive form. This problem arises because the normal-form criterion of maximizing expected utility at the beginning of the game imposes no constraints on players' behavior after an event that is perceived, at the beginning of the game, as having zero probability. A zero-probability event is often considered unimportant in probability theory, but an event in a game could get zero probability in a Nash equilibrium precisely because the predicted irrational behavior of players after this event would be so dangerous that players beforehand would feel rationally compelled to prevent it from happening.

This existence of such sequentially irrational Nash equilibria does not necessarily contradict our basic argument for Nash equilibrium as a general solution concept, if we recognize 
that this argument actually only established normal-form Nash equilibrium as a necessary condition for rational behavior. But then we have the problem of finding stronger necessary and sufficient conditions for rational behavior in extensive games. To try to solve this problem, Selten (1975) defined perfect equilibria as a refinement of Nash equilibrium for extensive and normal-form games, and Kreps and Wilson (1982) defined sequential equilibria as a fundamental noncooperative solution concept for extensive-form games.

As noted earlier, such refinements of Nash equilibrium were not unanticipated by Nash himself. In Nash (1951), a game with an imperfect equilibrium involving weakly dominated strategies was already found as Example 6, and a poker game was one of the first applications of behavioral-strategy analysis in the extensive form.

A second difficulty with the standard construction of the normal-form game is that it assumes that the "beginning of the game" must be a point in time when all players have the same information. This restriction can be awkward for modeling situations where players have longstanding differences in information, because it demands that our model must begin with some point from the distant past. John Harsanyi (1967-8) showed how to avoid this difficulty by constructing Bayesian game models of incomplete information. Harsanyi then defined a consistent Bayesian game to be one where the players' different beliefs at the beginning of the game could have been caused by their having observed different random variables, about which all players had common prior beliefs. (So a consistent Bayesian game can be recast in the framework of von Neumann's extensive form, with a chance move determining the players' types before the stage in which they choose their actions.)

When informational differences are used in applied theory to explain real economic 
behavior, the explanation is more convincing if these informational differences are not simply ad-hoc phenomena but can themselves be explained by differences in players' experiences. So Bayesian models that violate Harsanyi's consistency assumption can seem too ad hoc for convincing applied work. Thus, Harsanyi's general model of consistent Bayesian games became the standard analytical framework for information economics.

The interpretation of randomized-strategy equilibria was fundamentally changed by the introduction of the Bayesian games. Harsanyi (1973) showed that any randomized equilibrium of a normal-form game could be interpreted as a pure (nonrandomized) equilibrium of a very similar Bayesian game in which each player has some independent private information that affects the player's preferences in an arbitrarily small but strategically decisive way.

The interpretation of the normal form was modified in another way by Robert Aumann's (1974) definition of correlated equilibrium, for modeling communication among players. Nash had suggested that acts of communication among the players should be modeled as just another kind of move in the game. But Aumann defined the set of correlated equilibria of a given normal-form game so that it included all equilibria of all games that could be generated from the given game by allowing the players to make payoff-irrelevant communication moves before choosing their strategies in the given game. Aumann showed that, when we take this union of all equilibria that could be generated by all possible communication systems, we get a set that is characterized by a simple system of linear inequalities. Computing these correlated equilibria is often much easier than computing the Nash equilibria of the original game. Thus, we can simplify our analysis of games with communication by leaving the communication moves out of the game model and taking account of them in the solution concept instead. The extension of 
correlated equilibrium to Bayesian games with incomplete information is the set of incentivecompatible communication mechanisms, and the generalization of Aumann's insight (now known as the revelation principle) allows us to characterize the set of incentive-compatible mechanisms of any finite Bayesian game by a finite system of linear incentive constraints (see Myerson, 1982).

Thomas Schelling's (1960) concept of the focal-point effect addressed the crucial question of how to interpret a multiplicity of equilibria in a game. In a game with multiple equilibria, any factor which focuses the players' attention on one particular equilibrium may cause the players to rationally implement it, as a self-fulfilling prophecy. Thus Schelling argued that games with multiple equilibria should be understood as games where common cultural perceptions or historical traditions can have a decisive effect.

There is an interesting parallel between Schelling's (1960) focal-point effect for games with multiple equilibria and Harsanyi's (1973) purification of randomized equilibria. Harsanyi (1973) teaches us that, when we find randomized equilibria in a game, it means that each player's behavior may depend critically on something that the player knows privately, even if this factor has only a minor impact on his preferences. Schelling (1960) teaches us that, when we find multiple equilibria in a game, it means that the players' behavior may depend critically on something that the players know publicly, even if this factor has only a no intrinsic impact on their preferences. In each case, we are learning something about the predictive limits of economic analysis, because the social outcomes cannot be fully predicted simply by knowing the feasible strategies and preferences of all individuals. Understanding these limits does not devalue economics, but helps to redefine its relationship with the other social sciences. In 
particular, Schelling's focal point effect helps us to appreciate the importance of cultural traditions and social authority systems in economic affairs, even when individuals are perfectly rational.

So today we model games in normal form, in Bayesian form, and in extensive form. We analyze games by computing Nash equilibria, sequential equilibria, and correlated equilibria. The theory of noncooperative games that Nash founded has developed into a practical calculus of incentives that can help us to better understand the problems of conflict and cooperation in virtually any social, political, or economic institution.

\section{A Beautiful Mind}

But during these decades from 1960 to 1990, prolonged illness isolated John Nash himself from the economics community where his ideas were developing into a standard analytical methodology. Nash's writings provided a valuable intellectual guide and a rich source of research ideas for many of us who learned game theory in that period, but John Nash himself seemed a classic figure as removed from us as Cournot and Xenophon. From this perspective, Nash's recovery and re-entry into the active research community in recent years has appeared as an almost miraculous event, for which few had dared to hope.

The news of Nash's recovery was heralded by Sylvia Nasar (1994) in a beautiful article that was published in the New York Times about a month after Nash won the Nobel Prize with Harsanyi and Selten. Rarely in history of journalism has a newspaper reporter been able to do so much to give established academic specialists their first personal glimpse of a living colleague.

Nasar's (1998) full length biography of John Nash was the result of years of further 
research after this article. The book contains fascinating vignettes about the mathematical communities at Princeton in the 1940s and the RAND Corporation in the 1950s. There is a detailed discussion of how Nash as a young professor came to develop his extraordinary contributions to geometry and nonlinear systems, but there is rather less information about the creative process by which Nash as a graduate student developed his great contributions to game theory. We cannot help being curious about the history of these developments, because they are so important to us. What graduate student has not wished that, after taking just one formal course in a field, he could write a 27-page dissertation that would be hailed as a great intellectual breakthrough by scholars in generations to come? We want to know how John Nash did it!

But a reader of Nasar's book is also confronted with the great suffering that followed in the wake of these triumphs. Nash himself chose not to cooperate with Nasar in writing this biography, and so we cannot assume that her depiction of his life coincides with his own experience of it. There are some hard chapters where a reader may welcome this margin of doubt.

In a concluding chapter entitled "The Greatest Auction Ever," Nasar tries to illustrate the contemporary importance of game theory by describing game theorists' critical role in the design of FCC auctions that raised billions of dollars for the US government. Auction analysis should certainly be counted as one of the most important applications of game theory, and the FCC auctions gave a practical demonstration of the power of auction analysis. But there is something unsatisfactory in this chapter, because it misses the primary importance of noncooperative game theory as a unifying general structure for economic analysis. The practical effects of such general conceptual structures are manifested, not in any one substantive application, but in the way that 
scholars make connections between applications, carrying insights from one area into another. So if we want to use auction analysis as an illustration of the contemporary importance of noncooperative game theory, we should look at the way that auction analysis is integrated into economic theory.

When traditional price theory was the only general framework for rigorous economic analysis, auctions had to be viewed as exceptions to the standard paradigms of the profession, and there is always something disturbing or irritating about such exceptions. So Vickrey's (1961) work on auctions could be recognized as clever and even as having some practical significance, but its inconsistency with the standard paradigms of the perfectly competitive market inevitably made many leading theorists uncomfortable about thinking very long about it. This tension might be responsible for Vickrey's important paper being published in a specialized finance journal, rather than one of the leading journals of general economic theory.

But auction papers like Vickrey's were viewed very differently by people in the next generation who were familiar with noncooperative analysis of Bayesian games. From this gametheoretic perspective, the analysis of auctions could be seen as an important example of the general problem of incomplete information in economics. So today, when young economists read standard economics textbooks like Kreps (1990) and Mas-Colell, Whinston, and Green (1995), they study auctions as a standard paradigm that offers insights which can be extended to the analysis of pure exchange economies, social choice problems, public project planning, bilateral bargaining problems, principal-agent incentive problems, insurance and adverse selection. With our modern game-theoretic framework, a microeconomics textbook can now present all these applications together in a chapter on the general problems of sharing 
information in economic systems.

\section{Economics transformed}

Weintraub (1992, page 3) remarks that major treatises of economic theory from the 1930s have a language and style that often seems foreign and primitive to economic theorists today, whereas leading articles from the 1950s generally seem more familiar and modern to us. Much of this modernity begins with the writings of John Nash, which can still be recommended as standard readings for students today. In his construction of a general framework for game theory, Nash formulated the basic vocabulary for a new language of economic analysis. Even in the heart of price theory, subsequent papers on general Walrasian equilibrium were strongly influenced by Nash in style and methodology.

Of course, Nash's noncooperative game theory is an abstract mathematical framework for economic analysis; it is not the economic analysis itself. To apply the methodology of noncooperative game theory, economists formulate and analyze game models of markets and other institutions of society. The abstract generality of noncooperative game theory means that a great range of applied situations can be studied with a wide variety of models. So the task for economic theorists in the generations after Nash has been to identify the game models that yield the most useful insights into economic problems. The ultimate goal of this work will be to build a canon of some dozens of game models, such that a student who has worked through the analysis of these canonical examples should be well prepared to understand the subtleties of competitive forces in the widest variety of real social situations.

Scholars in any academic discipline always need a methodology to give a framework to 
their inquiry and debate. Our methodologies enable us to see connections that may be obscure to the untrained layman. But we also are aware that our expertise is diminished beyond the scope of our methodology, and we learn to stay within its boundaries.

Before Nash, price theory was the one general analytical methodology available to economics. The power of price-theoretic analysis enabled economists to serve as highly valued guides in practical policy-making, to a degree that was not approached by scholars in any other area of social science. But even within the traditional scope of economics, price theory has serious limits. Bargaining situations where individuals have different information do not fit easily into standard price-theoretic terms. The internal organization of a firm is largely beyond the scope of price theory. Price theory can offer deep insights into the functioning and efficiency of a market system where clear and transferable property rights are assumed for all commodities, but price theory cannot be applied to study the defects of a nonprice command economy. In development economics, an exclusive methodological reliance on price theory can lead naturally to a focus on those aspects of the developing economy that can be formulated within the terms of price theory, such as savings rates and international terms of trade, with a relative neglect of other fundamental problems such as crime and corruption, which can undermine the system of property rights that price theory assumes.

The broader analytical perspective of noncooperative game theory has liberated practical economic analysis from these methodological restrictions. Methodological limitations no longer deter us from considering market and nonmarket systems on an equal footing, and from recognizing the essential interconnections between economic, social, and political institutions in economic development. 
So Nash's formulation of noncooperative game theory should be viewed as one of the great turning points in the long evolution of economics and social science. During the classical era of Adam Smith, economic theory first achieved a higher level of formal analytical rigor by using the linear algebra of prices and quantities in the vector space of commodity allocations, and this mathematical methodology in turn encouraged economists to define their field in terms of a focus on material goods. But in the century before Nash, there was a long movement to identify the determinants of economic transactions in rational individual decision-making. Following the success of this movement, the question of how to extend such rational-choice analysis to more general social situations was taken up by the early game theorists, and von Neumann's argument for the generality of the normal form provided the original foundation for Nash's theory of noncooperative games. Once Nash's fundamental theory was accepted, however, the subsequent refinement of noncooperative game theory after 1951 required a critical movement away from the normal form. With this game-theoretic methodology, the scope of applied economic analysis gradually broadened, until one could fruitfully redefine economics as being the study of rational competitive behavior in any institution of society. Thus, by accepting noncooperative game theory as a core analytical methodology alongside price theory, economic analysis has returned to the breadth of vision that characterized the ancient Greek social philosophers who gave economics its name. 


\section{REFERENCES}

Aumann, Robert J. 1974. "Subjectivity and correlation in randomized strategies." Journal of Mathematical Economics 1:67-96.

Bernoulli, Daniel. 1738. "Specimen theoriae novae de mensura sortis [Exposition of a new theory on the measurement of risk]," Commentarii Academiae Scientiarum Imperialis Petropolitanae 5:175-192. English translation by L. Sommer in Econometrica 22:23-36 (1954).

Bertrand, Joseph. 1883. "Review of Walras's 'Théorie mathématique de la richesse sociale,' and Cournot's 'Recherches sur les principes mathématiques de la théorie des richesses."' Journal des Savants 67:499-508. Translation by J. W. Friedman in Cournot Oligopoly, edited by A. F. Daughety, Cambridge University Press (1988), pages 73-81.

Borel, Emile. 1921. "La théorie du jeu et les equation intégrales à noyau symétrique gauche," Comptes Rendus de l'Académie des Sciences 173:1304-1308. English translation by L. J. Savage in Econometrica 21:97-100.

Cournot, Augustin. 1838. Recherches sur les Principes Mathématiques de la Théorie des $\underline{\text { Richesses. Paris: Hachette. English translation by N. T. Bacon, Researches into the }}$ Mathematical Principles of the Theory of Wealth, New York: MacMillan (1927).

Fellner, William. 1949. Competition Among the Few. New York: Knopf.

Fréchet, Maurice. 1953. "Emile Borel, initiator of the theory of psychological games and its application." Econometrica 21:95-124.

Harsanyi, John C. 1967-8. "Games with incomplete information played by 'Bayesian' players." Management Science 14:159-182, 320-334, 486-502. 
Harsanyi, John C. 1973. "Games with randomly disturbed payoffs: a new rationale for mixed-strategy equilibria." International Journal of Game Theory 2:1-23.

Hurwicz, Leonid. 1945. "The Theory of Economic Behavior." American Economic Review 35:909-952.

Kakutani, Shizuo. 1941. "A generalization of Brouwer's fixed point theorem." Duke Mathematical Journal 8:457-459.

Kaysen, Carl. 1945. "A revolution in economic theory." Review of Economic Studies 24:1-15. Kohlberg, Elon, and Jean-Francois Mertens. 1986. "On the strategic stability of equilibria." Econometrica 54:1003-1037.

Kreps, David. 1990. A Course in Microeconomic Theory. Princeton University Press.

Kreps, David, and Robert Wilson. 1982. "Sequential equilibria." Econometrica 50:863-894.

Kuhn, Harold W. 1950. "Extensive Games." Proceedings of the National Academy of Sciences U.S.A. $36: 570-576$.

Kuhn, Harold W. 1953. "Extensive games and the problem of information." In H. W. Kuhn and A. W. Tucker, editors, Contributions to the Theory of Games I, pages 193-216, Princeton University Press.

Kuhn, Harold W., editor. 1994. "Nobel seminar: the work of John Nash in game theory." (With contributions by J. F. Nash, J. C. Harsanyi, R. Selten, J. W. Weibull, E. van Damme, and P. Hammerstein.) Les Prix Nobel 1994, 274-310.

Leonard, Robert J. 1994. "Reading Cournot, reading Nash: the creation and stabilisation of the Nash equilibrium." Economic Journal 104:492-511.

Marshak, Jacob. 1946. "Neumann's and Morgenstern's new approach to static economics." 
Journal of Political Economy 54:97-115.

Mas-Colell, Andreu, Michael D. Whinston, and Jerry R. Green. 1995. Microeconomic Theory. Oxford University Press.

Milnor, John. 1995. "A Nobel Prize for John Nash." Mathematical Intelligencer 17(3):11-17. Morgenstern, Oskar. 1976. "The collaboration between Oskar Morgenstern and John von Neumann on the theory of games." Journal of Economic Literature 14(3):803-816.

Myerson, Roger B. 1982. "Optimal coordination mechanisms in generalized principal-agent problems." Journal of Mathematical Economics 10:67-81.

Myerson, Roger B. 1992. "Fictitious-transfer solutions in cooperative game theory," in Rational Interaction, edited by R. Selten, Springer-Verlag, pages 13-33.

Myerson, Roger B. 1996. "John Nash's contributions to economics." Games and Economic Behavior 14:287-295.

Nasar, Sylvia. "The lost years of a Nobel laureate." New York Times, November 13, 1994, Section 3.

Nasar, Sylvia. 1998. A Beautiful Mind. New York: Simon \& Schuster.

Nash, Jr., John F. 1950a. "The bargaining problem." Econometrica 18:155-162.

Nash, Jr., John F. 1950b. "Equilibrium points in n-person games." Proceedings of the National Academy of Sciences U.S.A. 36:48-49.

Nash, Jr., John F. 1951. "Noncooperative games." Annals of Mathematics 54:289-295.

Nash, Jr., John F. 1953. "Two-person cooperative games." Econometrica 21:128-140.

Nash, Jr., John F. 1996. Essays on Game Theory. (With an introduction by K. Binmore.) Cheltenham, UK: Edward Elgar. 
Nash, Jr., John F. and Lloyd S. Shapley, "A simple three-person poker game," in H. W. Kuhn and A. W. Tucker, editors, Contributions to the Theory of Games I [Annals of Mathematical Studies 24l, Princeton U Press (1950).

Niehans, Jurg. 1990. A History of Economic Theory. Baltimore: Johns Hopkins University Press.

Rubinstein, Ariel. 1995. "John Nash: the master of economic modeling." Scandinavian Journal of Economics 97:9-13.

Schelling, Thomas. 1960. Strategy of Conflict. Harvard University Press.

Selten, Reinhard. 1965. "Spieltheoretische Behandlung eines Oligopolmodells mit Nachfragetragheit." Zeitschrift fuer die gesampte Staatswissenschaft 121:301-329, 667-689.

Selten, Reinhard. 1975. "Reexamination of the perfectness concept for equilibrium points in extensive games." International Journal of Game Theory 4:25-55.

Stone, Richard. 1948. "The Theory of Games." Economic Journal 58:185-201.

Van Damme, Eric and Jorgen W. Weibull. 1995. "Equilibrium in strategic interaction: the contributions of John C. Harsanyi, John F. Nash, and Reinhard Selten." Scandinavian Journal of Economics 97:15-40.

Vickrey, William. 1961. "Counterspeculation, auctions, and competitive sealed tenders. Journal of Finances 16:8-37.

Von Neumann, John. 1928. "Zur Theories der Gesellschaftsspiele." Mathematische Annalen 100:295-320. English translation by S. Bergmann in R. D. Luce and A. W. Tucker, eds., Contributions to the Theory of Games IV (1959), pp. 13-42, Princeton University Press. Von Neumann, John. 1953. "Communication on the Borel notes." Econometrica 21:124-125. 
Von Neumann, John and Oskar Morgenstern. 1944. Theory of Games and Economic Behavior. Princeton University Press. Second edition, 1947. Third edition, 1953.

Wald, Abraham. 1947. "Review of Theory of Games and Economic Behavior." Review of Economic Statistics 29:47-52.

Weintraub, E. Roy. 1992. Toward a History of Game Theory (annual supplement to volume 24 of History of Political Economy). Durham: Duke University Press.

Wilson, Edward O. 1998. Consilience: The Unity of Knowledge. New York: Alfred A. Knopf. 